\title{
From sustainable habits to sustainable energy use: social sustainability in the context of digitization
}

\author{
Maria Skivko ${ }^{*}$, Elena Korneeva $^{2,3}$, Olga Korableva $^{3,4}$ \\ ${ }^{1}$ Samara National Research University, 34, Moskovskoye shosse, Samara, 443086, Russian Federation \\ ${ }^{2}$ Financial University under the Government of the Russian Federation, 49, Leningradsky Prospekt, \\ Moscow, 125993, Russian Federation \\ ${ }^{3}$ Togliatti State University, 14, Belorusskaya St., Togliatti, 445667, Russia \\ ${ }^{4}$ Volga Region State University of Service, 4, Gagarina str., Togliatti, 445017, Russia \\ Togliatti State University, 14, Belorusskaya St., Togliatti, 445667, Russia
}

\begin{abstract}
This paper focuses on the social pillar of sustainability and explores the interconnection between social habits and conscious consumer choice in digital time. In particular, the paper analyses the digital culture's involvement in all areas of today's human life, and its possibility to define, transform, and interpret various social values and attitudes. At the examples of "green" apps use and "green" blogs following, this paper demonstrates how digital culture offers instruments and information for the development and diffusion of sustainable habits, in particular for dealing with sustainable energy use. Moreover, some considerations regarding the benefits of digital culture for business strategies and sustainable community development through digitization are proposed.
\end{abstract}

\section{Introduction}

Nowadays, the concept of sustainability affects many areas of human activities. Furthermore, it evolves rapidly, provokes discussion at the national and international levels, and inspires innovations and innovative approaches in various industries and business sectors. These innovations and the evolution of sustainable discussion at the level of an average consumer transform consumer preferences and result in some transformations in social values and social habits. The development of digital media and digital communication strengthens the sustainable discussion in the digital space providing access to information about sustainable practices to everyone. This article highlights the potential of green blogs and green apps to implement sustainable habits into the everyday routine and motivate to further follow them by using digital devices. In particular, the article explains the possibility of applying the practice of domestic sustainable energy consumption with the help of green bloggers and green mobile apps.

\footnotetext{
${ }^{*}$ Corresponding author: maria.skivko@gmail.com
} 
Although the concept of sustainability has many interpretations and applications, there is still no universal definition of its pillars, especially of the notion of social sustainability [1]. Generally, it may concern social values and social standards, social institutions and participation, equal opportunities, or democratic rights. By connecting environmental protection with social justice through political involvement, social sustainability is responsible for harmonic interaction between people and the environment. Moreover, social sustainability defines, articulates, and regulates those social values and social attitudes that ensure social welfare for future generations.

Many scholars emphasize that social sustainability has not been explored enough, and no clear definition has been given yet. Thence, some researchers pay more attention to explaining socially oriented practices that influence the construction of conceptual framework [2,3]. Others use the list of indicators that articulate social sustainability's main tasks in the modern world [4,5]. Littig and Griessler define social sustainability as a "quality of societies" that is expressed through the interaction of people and nature and expresses the satisfaction of basic and extended human needs without harming natural sources over time and notions of social justice, social participation, and human dignity are taken into account [6]. As Boström argues, social aspects of sustainability deserve more attention from the theoretical perspective and empirical investigation due to its ability to be incorporated into the sustainable practices and facilitate changes from the individual perspective [7].

As far as sustainable development generally aims to fulfil the needs of the present generation, not affecting future generations' needs, it is possible to suggest that the social sustainability concept embraces mainly the area of human demands. Talking about basic needs (e.g., food, access to water, housing, health care, sexuality) and additional needs (e.g., education, social relationship, leisure) concerns the relationship between human behaviour and nature. This is the expression of social sustainability articulated in lifestyle, habits, and social practices.

This article considers social sustainability under the scope of interaction between social habits and social well-being. Social habits impact individuals' conditions and quality of life; the switch to sustainable social habits can improve living conditions and lower the negative environmental effect by using sustainable alternatives and practices.

\section{Social habits, digitization, and conscious consumption}

Social habits as a way of behaviour towards others can be determined and influenced by the social environment, cultural background, education, or particular lifestyle. Moreover, social habits as regular practices are deeply connected to the consumer behaviour patterns: individuals follow the same social attitudes, consumer standards, and consumer preferences by regular or particular shopping occasions.

Nowadays, it is possible to suggest that digitization, technological progress and the possibilities of digital communication also determine social habits and consumer preferences. Digital technologies participate in many everyday activities of individuals aiming to simplify routine tasks and improve the quality of life (to remind, control, calculate, measure). In the digital space today, it is possible both to do business and to entertain oneself: doing shopping, studying, working, and communicating became possible due to the technologies and digitization, almost without borders and limitations.

Furthermore, access to the specific types of information has dramatically changed in the last years. The development of social media simplified digital communication and defined new opinion leaders. Those new authorities prefer to use digital technologies and digital media (microblogs, video channels, social networks accounts, blogs) for sharing their personal experience, expertise, or any specific information $[8,9]$. Plenty of bloggers occupy 
people's minds today and due to the access to information and the internet attract followers from all over the world.

Therefore, these digital authorities, bloggers, transmit not only their opinion but their habits, daily routine, social and cultural values, and individual interests. Besides, they determine consumer trends in various areas. They share the details from private life and motivate their followers to repeat the patterns. For instance, fashion bloggers, mostly women, demonstrate ideal fashioned bodies, fancy outfits, and perfect makeup, promoting the standards of beauty and creating an ideal visual image. As another example, food-bloggers can share their secrets of cooking, promote any nutritional diet, or create food experiments and motivate followers to increase their interest in cooking, gastronomic secrets, or nutrition.

Bloggers today represent the model of consumption created in the digital space that interacts with followers and influences their social habits. Some bloggers support the idea of extensive consumption, for example, and emphasize the importance of following fashion trends - in the same way regarding clothes, accessories, beauty products, or electronic devices and cars. Others, those who share and promote sustainable habits for everyday life, can have the same power to influence and determine the social habits of followers under the sustainable perspective [10].

With climate change, the risk of global warming, and some hazardous consequences for the world economy, today's sustainable discussion develops not only at the world politics level. At the regular consumer level, it becomes essential to be aware of the outcomes of climate change, sustainable use of resources, and sustainable alternatives for the everyday routine. Digitization and digital culture expanded the ways to find the relevant information, talk about the environment and sustainability, and spread the environmental news around the globe.

In these circumstances, bloggers can become this source of necessary information and expertise to define, promote, and explain common sustainable habits. Conscious consumption that is connected to sustainable habits can change its role from the pattern of a small group of adepts of sustainable practices to the main pattern for the majority. Using different forms and types of context (personal stories, visual data, results of individual experiments), bloggers sometimes articulate these topics that are not often covered by the conventional media. Moreover, bloggers can attract attention to quite complicated topics and provoke relevant discussion in digital media. This discussion shapes the representation of sustainability in the digital space.

\section{Green blogs for sustainability}

Blogs today are considered as a strong marketing instrument to affect consumer behaviour [11]. The more sustainable discussion spread to the world, the more it intervenes in the digital space and personal blogs. Among the variety of blogs, it is relevant to mention those that: i) talk professionally about sustainability (e.g., climate change, greenhouse effect, carbon footprint); ii) promote a sustainable lifestyle and everyday practices (e.g., zero-waste lifestyle, minimalism, principles of reuse, reduce, recycle); iii) explain different topics under the sustainable perspective (e.g., sustainable fashion, sustainable architecture, sustainable art).

In the first case, confirmed field experts provide the approved knowledge on specific topics. Work professionals, academics, coaches, popular speakers for sustainability talk about individual responsibility in consumption and advocate for changes through arguments and scientific data. Expert knowledge is based on facts and less present the daily routine cases, so these blogs' potential audience should have a true interest in the promoted topics. Special attention should be given to big corporations' green blogs (e.g., Google, Microsoft) 
that also join the sustainable discussion and explain the sustainable agenda from the corporate perspective and their particular input $[12,13,14]$.

In the second case, non-experts and non-celebrities express their interest and involvement in sustainability and share with follower's specific knowledge based on practice. These sustainable, or green, bloggers can, at the examples from individual experience and personal daily routine, explain and articulate several norms, regulations, and ideas of sustainability and provide useful advice and tips for sustainable living [15]. They explain how to organize garbage and recycling at home, test new organic skincare or cleaning products, or calculate how much money it is possible to save just by switching off the house's light. Those bloggers transform the ideas of individual responsibility, social values, social involvement, readiness for sustainable development changes into an easy-going discussion, using typical instruments of blogging and marketing (e.g., story-telling, visualization, experiments, tests). This type of content is quite common and popular in the digital space; the audience follows and tracks the everyday sustainable patterns and tends to repeat them at home. Some of these bloggers are well-known globally for their innovative interpretation of sustainable ideas, such as living zero-waste as Bea Johnson [16] or possessing a minimum of stuff and still staying happy as the Minimalists [17].

The third case can be presented by various bloggers from different topics: fashion and beauty industries, architecture, arts, health care, nutrition and diets. As far as the sustainable discussion is growing and concerns more and more areas of human life, even for bloggers, there is much potential to produce new digital content by uncovering the possibilities of sustainable perspective in different subjects. Consumption and fashion are deeply interrelated, and, for instance, fashion bloggers today are those influencers who define many consumer preferences and consumer behaviour models, describe current trends, promote designers, and give inspiration. So, sustainable fashion bloggers talk about all these things but under the sustainable perspective (e.g., fair conditions of clothes production, raw materials extraction, eco-friendly technologies, labour rights, recycling of items) [18]. These bloggers can promote as sustainable goods and services in the fashion industry as well as practices of sustainable consumption (including reuse, reduce, recycling principles).

What is important to mention is the power of social media influencers. On the one hand, they can help regular consumers change their everyday habits into sustainable ones. On the other hand, any business can benefit from collaborating with bloggers to promote their goods and services more sustainably.

Green bloggers writing about sustainable energy use explain how to make a home a bit more sustainable: it can involve advice on planning and budgeting expenses for household, advantages and disadvantages of using smart meters or solar panels, specifics of low carbon heating, or energy-saving and eco-friendly practices. Performing this information in the readable for everyone form, green bloggers promote how to have a comfortable and healthy home with affordable energy-efficient consumption. The energy efficiency topic can be for someone a complicated issue, especially regarding the ways how to implement it in the household; with the help of green bloggers, it seems to become possible to promote the sustainable practices of energy consumption and efficient business solutions (e.g., use of renewable energy, smart meters, solar grids) for this task.

\section{Green apps and sustainable energy use}

Particular attention should be given to green, or sustainable apps. With the development of sustainable discussion that challenges many industries to become greener and produce less negative environmental impact, the green IT concept started to develop and attracts the attention of business, mainly start-ups, and conscious consumers [19, 20]. Green IT can be understood as practices of environmentally sustainable computing and IT that aim to reduce 
the use of hazardous materials, maximize energy efficiency, and lower negative environmental impact (e.g., using green hosting provider, image optimization, removing unused features from apps). Such instruments as environmental internet portals, professional or personal blogs, wikis, or interactive simulations of the environmental impact of different consumer practices represent the ways of environmental involvement and the strategies to deal with it at the global and local levels.

Green apps aim to help users join the global movement of sustainable development ideas at the local level of everyday practices and consumer behaviour. In other words, the development of green apps can foster progress in sustainable development. Green apps can be used in the private household or at work; in both cases, they can give suitable information about certain sustainable habits, the necessity to change consumer behaviour, or the advantages of using those digital technologies in everyday life. Moreover, they can establish and support the motivation to follow a sustainable lifestyle, in some cases by compensating or rewarding.

For example, some apps use gamification principles to attract users by the habitual format; by setting the final goal and game rules, these apps support users in this game to create a sustainable habit [21]. Feedback and app support settle productive results in creating a habit and increasing the users' motivation to continue those practices.

Regarding the energy use apps, it is possible to denote the ways how they perform the information, for instance, as an educational tool (lectures, video materials, illustration), entertainment (games), source of various information (useful tips, guides, check-lists, recommendations, indicators), transformation tool (to control, measure, plan, analyze the consumption) [22].

By talking about energy use apps, it is important to mention that one of the efficient ways to attract followers' attention is to motivate them through financial benefits. Not every consumer is ready to change everyday habits just for the benefits of the environment; but the most would instead do that if they get the advantages for the household budget provided. So, many energy use apps primarily emphasize those tools implemented that help calculate the costs, track, and control consumer use of energy to save money or get some extra bonuses.

Thence, financial motivation for sustainable habits can be considered one of the most influential instruments in communication with consumers. Green apps help to define which home appliances consume the most energy, energy usage and energy consumption per day, per week, or per month; some of them provide additional services as, for instance, real-time tracking, remote control, save the history of energy consumption, or just easy tips for saving energy and rational energy consumption.

The easier is the app to install and configure, the more chances it has to stay in the household as a helpful tool. Smartphone, tablets, or wearables with different sensors and hardware modules allows to learn new information and apply it at the practice immediately; ubiquitous access to information through digital technologies shapes the priorities of new generations.

Any business that applies green IT in its production process can expect the brand's image benefits. Moreover, it can foster investments or collaboration for the sustainable advocacy, and decrease certain expenses by using innovative sustainable technologies.

\section{Conclusions}

Generally, our article presented the perspective on green blogs and green apps as powerful instruments to influence consumers and create sustainable social habits. As the social pillar of sustainability, social habits represent the intention for social well-being and conscious consumption. In the world of digital technologies and digital communication, it becomes easier to introduce, control, monitor, and check various social habits with the help of digital 
devices and the expert opinion of digital influencers. Additionally, from the marketing perspective, these digital tools and authorities can be considered quite significant instruments for business development, especially in the case of start-ups developing mobile apps.

It is true that the information from bloggers can be considered dually, as a source of unconventional truth and experience or as a source of low-quality information that is difficult to check. It also makes sense to differentiate professional green blogs and personal green blogs that produce and deliver different types of information and the opinion of a different quality. However, the fact that environmental discussion in the digital space is growing every year means the implementation of sustainable practices and habits into everyday reality.

Green apps that help to monitor domestic energy consumption are considered as a technological innovation that can be applied at every household with the help of digital devices. Additionally, green apps facilitate the spread of environmental knowledge among individual consumers and motivate them to join the community of conscious consumers and benefit from this lifestyle.

Furthermore, the business sector can also get some benefits and profits from collaborating with green bloggers and supporting the development of green apps. Such collaboration strengthens the advocacy for sustainable discussion changes and raises questions about individual responsibility and individual choice for a sustainable lifestyle and social practices.

\section{References}

1. R. H.W. Boyer, N.D. Peterson, P. Arora, K. Caldwell, Sustainability, 8(9), 878 (2016)

2. J. Lu, L. Ren, J. Qiao, S. Yao, W. Strielkowski, J. Streimikis, Sustainability, 11(15), 4128 (2019)

3. N. Dempsey, G. Bramley, S. Power, C. Brown, Sustainable Development Bradford, 19(5), 289 (2011)

4. S. McKenzie, Hawke Research Institute working paper series. University of South Australia 2004. 27: https://tmuk.pw/socialsustainability.pdf

5. M. Missimer, K.-H. Robèrt, G. Broman, Journal of Cleaner Production, 140, 32 (2017)

6. B. Littig, E. Griessler, International Journal of Sustainable Development, 8, 1 (2005)

7. M. Boström, Sustainability: Science, Practice and Policy, 8(1), 3 (2012)

8. M. Pedroni, Film, Fashion \& Consumption, 5(1), 103 (2016)

9. D. Jiménez-Castillo, R. Sánchez-Fernández, International Journal of Information Management, 49, 366 (2019)

10. J. Haider, Journal of Documentation, 68(5), 639 (2012)

11. S.-C. Chen, C.-P. Lin, Technological Forecasting and Social Change, 96, 40 (2015)

12. Google Sustainability blog: https://blog.google/outreach-initiatives/sustainability/

13. Microsoft Green Blog: https://blogs.microsoft.com/green/

14. Panasonic Green Living: https://na.panasonic.com/us/green-living

15. S. Joosse, T. Brydges, Environmental Communication, 12(5), 686 (2018)

16. Zero Waste Home: https://zerowastehome.com/blog

17. The Minimalists: https://www.theminimalists.com

18. M.L. LeHew, S.U. Patwary, Paper presented at the Third International Conference of the Sustainable Consumption Research and Action Initiative (SCORAI), Copenhagen, Denmark, 27-30 June 2018

19. S. Murugesan, IT Professional, 10(1), 24 (2008)

20. F. Loeser, Paper presented at 19th Americas Conference on Information Systems (AMCIS)At: Chicago, IL, August 2013

21. G. Rausser, W. Strielkowski, D. Štreimikienè, Energy \& Environment, 29(1), 131-146 (2018) 
22. B. Brauer, C. Ebermann, B. Hildebrandt, G. Remane, L.M. Kolbe, Paper presented at the Conference: Proceedings of 20th Pacific Asia Conference on Information Systems (PACIS 2016), Chiayi, Taiwan (2016) 